\title{
Striatal and nigral muscarinic type 1 and type 4 receptors modulate levodopa-induced dyskinesia and striato-nigral pathway activation
}

\author{
Alberto Brugnoli ${ }^{1}$, Clarissa Anna Pisanò ${ }^{1}$, and Michele Morari ${ }^{1}$ \\ ${ }^{1}$ University of Ferrara
}

May 5, 2020

\begin{abstract}
Background and purpose: Muscarinic receptors contribute to both the facilitation and inhibition of levodopa-induced dyskinesia operated by striatal cholinergic interneurons, although the receptor subtypes and the mechanisms involved have not been clearly identified. Also muscarinic receptors in substantia nigra reticulata, activated by cholinergic midbrain afferents, regulate striatal functions although their role in levodopa-induced dyskinesia remains to be proven. Here, we investigate whether striatal and nigral muscarinic M1 and/or M4 receptors modulate dyskinesia expression and the underlying striato-nigral GABAergic pathway activation in 6-hydroxydopamine hemilesioned rats. Experimental approach: Reverse microdialysis allowed to deliver the M1 and M4 preferential antagonists telenzepine, PD-102807, tropicamide and the selective M4 positive allosteric modulator VU0152100 in striatum or substantia nigra, while levodopa was administered systemically. Dyskinetic movements were monitored along with nigral GABA (and glutamate) and striatal glutamate levels, taken as neurochemical markers of striato-nigral pathway activation. Key results: Intrastriatal telenzepine, PD-102807 and tropicamide alleviated dyskinesia and inhibited nigral GABA and striatal glutamate release. This was partially replicated by intrastriatal VU0152100 that, however, failed to inhibit striatal glutamate. The M2 preferential antagonist AFDX-116, used to elevate striatal acetylcholine levels, blocked the behavioral and neurochemical effects of PD-102807. Intranigral VU0152100 prevented levodopa-induced dyskinesia and its neurochemical correlates whereas PD-102807 was ineffective. Conclusions and Implications: Striatal M1 and M4, likely postsynaptic, receptors facilitate dyskinesia and striato-nigral pathway activation. Striatal M4 receptors, possibly located presynaptically, also inhibit dyskinesia. Potentiation of striatal and nigral M4 transmission leads to powerful multilevel inhibition of striato-nigral pathway providing a new strategy to tackle dyskinesia.
\end{abstract}

\section{Non standard abbreviations}

LID, levodopa-induced dyskinesia; AUC, area-under-the-curve; AP, antero-posterior; BG, basal ganglia; ChIs, cholinergic interneurons; DA, dopamine; DLS, dorsolateral striatum; PPN, pedunculopontine nucleus; DV, dorso-ventral; ML, medio-lateral; PAM, positive allosteric modulator; Glu, glutamate; 6-OHDA, 6hydroxydopamine; levodopa, L-DOPA; PD, Parkinson's disease; SNr, substantia nigra pars reticulata; TH, tyrosine hydroxylase.

\section{Bulleted point summary}

\section{What is already known}

- Non-selective muscarinic antagonists and ablation or functional inhibition of striatal cholinergic interneurons inhibit levodopa-induced dyskinesia

- Striatal M4 receptor activation reduces levodopa-induced dyskinesia in mice and non human primates

\section{What this study adds}

- Both striatal M1 and M4 muscarinic receptors mediate levodopa-induced dyskinesia and striato-nigral pathway activation 
- Striatal and nigral M4 muscarinic receptor stimulation attenuate levodopa-induced dyskinesia and striato-nigral pathway activation

\section{Clinical significance}

M4 muscarinic receptor agonists might prove effective in palliating levodopa-induced dyskinesia

\section{Introduction}

The contribution of striatal cholinergic interneurons (ChIs) to striatal functions and parkinsonism has long been recognized (Calabresi et al. , 2000; Pisani et al. , 2007). In the last decade, the role of striatal ChIs in levodopa (L-DOPA) induced dyskinesia (LID) has also emerged (Bordiaet al. , 2019; Moehle et al. , 2019). Dyskinesia is a major side-effect of L-DOPA pharmacotherapy of Parkinson's disease (PD), and is clinically characterized by abnormal involuntary movements (AIMs) of dystonic and choreic nature (Bastide et al. , 2015). LID has a complex and partially unknown etiology, but the final neurobiological event is the sensitization of D1 expressing striato-nigral GABAergic medium-sized spiny neurons (MSNs) to L-DOPA (Bastide et al. , 2015). Striatal ChIs profusely innervate both striato-pallidal and striato-nigral MSNs and influence their activity either directly or indirectly, via modulation of dopamine, serotonin, glutamate release from striatal afferents, and GABA release from striatal interneurons. It was originally found that ablation or functional inhibition of ChIs attenuate LID (Ding et al. , 2011; Won et al. , 2014), although a more recent optogenetic study revealed that ChIs dually modulate LID, facilitating it at low firing rates and attenuating it at higher ones (Bordia et al. , 2016). Pharmacological studies showed that both muscarinic (Bordia et al. , 2016; Chambers et al. , 2019; Ding et al. , 2011; Shen et al. ,2015) and nicotinic (Quik et al. , 2015) receptors are involved in LID. However, while it has been convincingly demonstrated that nicotinic receptor blockade (with receptor antagonists) or desensitization (with receptor agonists) prevents LID (Quik et al. , 2015), the role of muscarinic receptors is far from clear (Bordia et al. , 2019). This might be due to the different neuronal distribution and functional roles of muscarinic receptor subtypes. In fact, muscarinic receptors are GPCR belonging to two major families which couple to $\mathrm{G}_{\mathrm{i} / \mathrm{o}}$ (M2 and M4 subtypes) or $\mathrm{G}_{\mathrm{q} / 11}$ (M1, M3 and M5 subtypes), and are unevenly distributed on the different populations of striatal neurons and nerve terminals. In particular, striato-pallidal MSNs predominantly express M1 receptors, while striato-nigral MSNs express both M1 and M4 receptors (Bernard et al. , 1992; Hersch et al. , 1994). The M4 receptor is considered the main autoreceptor type at striatal ChIs (Zhang et al. , 2002), although also M2 autoreceptors contribute to negative auto feed-back (Bonsi et al. , 2008). Another major problem in dissecting out the role of endogenous ACh and muscarinic receptor subtypes in LID is the poor selectivity of muscarinic antagonists available. Thus, the unselective muscarinic antagonists dicyclomine and atropine prevented LID in 6-hydroxydopamine (6-OHDA) hemilesioned mice (Bordia et al. , 2016; Ding et al. , 2011) whereas atropine also prevented LID inhibition induced by optogenetic elevation of ChIs firing rates (Bordia et al. , 2016). M4 selective positive allosteric modulators (PAMs) reduced LID in murine and non-human primate models of LID, pointing out a crucial role for M4 receptors in this movement disorder (Shen et al. , 2015). In partial agreement, the putative M4 "preferential" antagonist tropicamide (Lazareno et al. , 1993; Lazareno et al. , 1990) worsened AIMs induced by L-DOPA but attenuated those induced by a D1 receptor agonist in 6-OHDA hemilesioned rats (Chambers et al. , 2019), suggesting the involvement of different sets of M4 receptors. However, the M4 "selectivity" of tropicamide, if any (Croy et al. , 2016), is negligible which calls for a re-evaluation of its effects with relatively more selective compounds. Finally, the role of ACh in LID might extend beyond striatal ChIs. In fact, cholinergic inputs from the pedunculopontine tegmental nucleus (PPN) modulate basal ganglia function (Xiao et al. , 2016), and D1 signaling at striato-nigral MSNs terminals (Moehle et al. , 2017). Although a preliminary report showed that injection of tropicamide in PPN did not modulate LID expression (Chambers et al. , 2019), whether M4 receptor stimulation or blockade in SNr shape LID remains to be established.

In the present study, in vivo dual probe microdialysis was used to clarify the role of striatal and nigral M1 and M4 receptors in the modulation of LID and the underlying striato-nigral MSNs activation. A reverse microdialysis approach was adopted to deliver the M1 and/or M4 preferential antagonists telenzepine, PD-102807, tropicamide as well as the selective M4 PAM VU0152100 in the dorsolateral striatum or SNr, concurrently 
with systemic L-DOPA administration. This approach had the two-fold advantage of i) targeting muscarinic receptors in specific brain areas, ii) minimizing the poor selectivity of muscarinic receptor antagonists by setting pharmacological selective concentrations in the perfusion Ringer (see Methods). Dyskinetic behavior was monitored concurrently with GABA release in SNr, a readout of striato-nigral MSNs activation (Marti et al. , 2012; Mela et al. , 2012; Mela et al. , 2007), and glutamate release in striatum, a possible index of cortico-basal ganglia-thalamo-cortical loop activation (Bastide et al. , 2015). The feasibility of this approach was previously demonstrated showing that reverse dialysis of the D1 antagonist SCH23390, but not the D2 antagonist raclopride, in striatum prevented LID and its neurochemical correlates (Mela et al. , 2012).

\section{Methods}

Animal subjects

Experimental procedures involving the use of animals complied with the ARRIVE and BJP guidelines. Male Sprague-Dawley rats (Charles River Lab, Calco, Lecco; Italy) were housed in a standard facility with free access to food (4RF21 standard diet; Mucedola, Settimo Milanese, Milan, Italy) and water, and kept under regular lighting conditions ( $12 \mathrm{hr}$ dark/light cycle). Animals were housed in groups of two in an 850 $\mathrm{cm}^{2}$ polysulfone cage (OptiRat; Animal Care Systems, Centennial, CO, USA) with a Scobis Uno bedding (Mucedola, Settimo Milanese, Milan, Italy) and environmental enrichments. Adequate measures were taken to minimize animal pain and discomfort. Experimental protocols were approved by the Ethical Committee of the University of Ferrara and the Italian Ministry of Health (license 714/2016-PR).

Unilateral 6-OHDA lesion

Rats $(150 \mathrm{~g})$ were unilaterally injected in the (right) medial forebrain bundle with $8 \mu \mathrm{g}$ 6-OHDA hydrobromide (dissolved in $0.02 \%$ ascorbate-saline), according to the following stereotaxic coordinates from bregma and the dural surface (in mm): antero-posterior (AP) -4.4, medio-lateral (ML) 1.2, ventro-dorsal (VD) -7.8, tooth bar at -2.4 mm (Paxinos et al., 1986), as previously described (Mela et al., 2012; Morari et al., 1996; Paolone et al., 2015). Animals were pretreated with antibiotics (Synulox ${ }^{\mathrm{TM}}, 50 \mu \mathrm{kg}^{-1}$, i.p.). The wound was sutured and infiltrated with $2 \%$ lidocaine solution $\left(\right.$ Esteve $\left.^{\mathrm{TM}}\right)$. Two weeks later, rats were screened by assessing the motor asymmetry score in two different ethological tests (the bar and drag tests) (Pisanò et al., 2020). Rats showing immobility time at the contralateral paw in the bar test $>20 \mathrm{sec}$ and a number of steps at the contralateral paw $<3$ (or alternatively a contralateral/ipsilateral paw ratio $<50 \%$ ) were enrolled in the study (Pisanò et al., 2020).

\section{Microdialysis experiments .}

Dual probe microdialysis was performed as previously described (Mela et al., 2012; Morari et al., 1996; Paolone et al., 2015). Concentric microdialysis probes were constructed using AN69 (Gambro Industries, Meyzieu, France) semipermeable hollow membranes ( $65 \mathrm{kDa}$ molecular weight cut-off, $340 \mu \mathrm{m}$ outer diameter). Ninety-six (96) 6-OHDA fully dyskinetic rats (AIMs > 100) were used in the study. One microdialysis probe was stereotactically implanted under isoflurane anesthesia in the DA-depleted dorsolateral striatum and another in the ipsilateral SNr. Implantation coordinates (in $\mathrm{mm}$, from bregma and the dural surface) (Paxinos et al., 1986), and dialysis membrane lengths were: dorsolateral striatum, AP +1.0, ML $\pm 3.5, \mathrm{DV}$ -6.0 (3 mm), SNr, AP -5.5, ML $\pm 2.2, \mathrm{DV}-8.3(1 \mathrm{~mm})$. Twenty-four hours after surgery, probes were perfused with a modified Ringer solution $\left(\mathrm{CaCl}_{2} 1.2 \mathrm{mM}\right.$; KCl $2.7 \mathrm{mM}$; $\left.\mathrm{NaCl} 148 \mathrm{mM} ; \mathrm{MgCl}_{2} 0.85 \mathrm{mM}\right)$ at a $3 \mu \mathrm{l}$ $\mathrm{min}^{-1}$ flow rate. Sample collection (every $20 \mathrm{~min}$ ) started after $6 \mathrm{~h}$ rinsing. At least four baseline samples were collected, then treatments were administered in a randomized fashion. At the end of experiments, animals were sacrificed by an overdose of isoflurane, and the correct placement of the probes was verified histologically. Severe (93\%) dopamine depletion was randomly confirmed by post-mortem analysis of tyrosine hydroxylase (TH) levels in Western blot assay (optical density of TH band normalized over $\alpha$-tubulin: $0.22 \pm 0.04$ vs $3.13 \pm 0.39$ ipsilateral vs contralateral striatum, respectively, $\mathrm{t}=7.37 \mathrm{df}=19$, Student's t-test, two-tailed for unpaired data; $\mathrm{n}=20$ rats; Supplementary Figure 1).

LID induction and AIMs ratings 
6-OHDA hemilesioned rats received $6 \mathrm{mg} \mathrm{kg}^{-1} \mathrm{~L}$-DOPA (plus $12 \mathrm{mg} \mathrm{kg}^{-1}$ benserazide, s.c.), once a day for 21 days as originally described by MA Cenci and collaborators (Cenci et al. , 1998; Cenci et al. , 2007) and reported by our group (Marti et al. , 2012; Mela et al. , 2012; Paolone et al., 2015). Rats were observed individually for 1 min every 20 min during the $3 \mathrm{~h}$ that followed an L-DOPA injection. Dyskinetic movements were classified based on their topographic distribution into three subtypes: (i) axial AIMs, that is, twisted posture or choreiform twisting of the neck and upper body toward the side contralateral to the lesion; (ii) forelimb AIMs, that is, jerky or dystonic movements of the contralateral forelimb and/or purposeless grabbing movement of the contralateral paw; (iii) orolingual AIMs, that is, orofacial muscle twitching, empty masticatory movements and contralateral tongue protrusion. Each AIM subtype was rated on frequency and amplitude scales from 0 to 4 (Cenci et al. , 2007). Dyskinesia score was calculated either in the induction phase or during the microdialysis sessions, as the product of frequency x amplitude (Cenci et al. , 2007), and presented as cumulative AIMs score.

Endogenous Glu and GABA analysis

Glu and GABA in the dialysate were measured by HPLC coupled with fluorometric detection as previously described (Mela et al. , 2012; Paolone et al. , 2015). Thirty microliters of o-phthaldialdehyde/mercaptoethanol reagent were added to $30 \mu \mathrm{l}$ aliquots of sample, and $50 \mu \mathrm{l}$ of the mixture were automatically injected (Triathlon autosampler; Spark Holland, Emmen, Netherlands) onto a 5-C18 Hypersil ODS analytical column (3 mm inner diameter, $10 \mathrm{~cm}$ length; Thermo-Fisher, USA) perfused at a flow rate of $0.48 \mathrm{ml} \mathrm{min}^{-1}$ (Jasco PU-2089 Plus quaternary pump; Jusco, Tokyo, Japan) with a mobile phase containing 0.1 M sodium acetate, $10 \%$ methanol and $2.2 \%$ tetrahydrofuran $(\mathrm{pH}$ 6.5). Glu and GABA were detected by means of a fluorescence spectrophotometer FP-2020 plus (Jasco, Tokyo, Japan) with the excitation and the emission wavelengths set at 370 and $450 \mathrm{~nm}$ respectively. Under these conditions, the limits of detection for Glu and GABA were $\sim 1 \mathrm{nM}$ and $0.5 \mathrm{nM}$, and their retention times $\sim 3.5 \mathrm{~min}$ and $\sim 18.0 \mathrm{~min}$, respectively. Chromatogram analysis was made by a blinded experimenter using a dedicated ChromNav software (Jasco, Tokyo, Japan).

TH analysis

Rats were sacrificed by an overdose of isoflurane. Striata were solubilized and homogenized in lysis buffer (RIPA buffer, protease and phosphatase inhibitor cocktail) and centrifuged at 18,000 x g for 15 min at $4^{\circ} \mathrm{C}$ (Pisanò et al. , 2020). Supernatants were collected and total protein levels were quantified using the bicinchoninic acid protein assay kit (Thermo Scientific). Thirty micrograms of protein per sample were separated by SDS-PAGE, transferred onto polyvinyldifluoride membrane and incubated overnight $\left(4^{\circ} \mathrm{C}\right)$ with the rabbit anti-TH primary antibody (Merck Millipore, AB152, 1:1000). Membranes were then washed and incubated with horseradish peroxidase-linked secondary antibody (Merck Millipore, goat anti-rabbit IgG HRP-conjugate 12-348, 1:4000). Immunoreactive proteins were visualized by enhanced chemiluminescence (ECL) detection kit (Pierce BCA Protein Assay Kit, Thermo Scientific or ECL+, GE Healthcare). Images were acquired and quantified using the ChemiDoc MP System and the ImageLab Software (Bio-Rad). Membranes were then stripped and re-probed with rabbit anti- $\alpha$-tubulin antibody (Merck-Millipore 04-1117, 1:25000). Data were analyzed by densitometry and the optical density of TH protein band was normalized to $\alpha$-tubulin levels.

\section{Experimental design}

Dyskinetic rats were randomized to L-DOPA or L-DOPA in combination with a muscarinic ligand in the Day 1 microdialysis session, and treatments were crossed in the Day 2 session. Experimenters were blinded to treatments. Groups were balanced in terms of Day 1 or Day 2 treatments. The effect of muscarinic ligands OFF L-DOPA was investigated in separate groups of rats. In this case, one rat received two different ligands, randomized in Day 1 and Day 2 sessions in a balanced design.

Perfusing muscarinic antagonists through the microdialysis probe allowed to deliver constant amount of compounds in the selected brain areas so to set stable and pharmacologically selective levels, approximating the affinity values for the targeted receptor, in the extracellular space. This was accomplished by taking into account in vitro recovery, which in our microdialysis conditions, with the $3 \mathrm{~mm}$ probe implanted in 
striatum, approximates $10 \%$. We therefore estimated that roughly one tenth of the nominal concentration of the compound in the perfusion Ringer would be delivered to the extracellular space. Considering the poor selectivity of muscarinic receptor antagonists, this approach might represent an advantage over classical microinjection protocols. Telenzepine is an M1 receptor preferential antagonist, with an affinity of 1-3 nM for M1 receptors, a 2-5 fold selectivity for M1 over M4 receptors, and a 5-30 fold selectivity for M1 over M2, M3 and M5 receptors (Doods et al. , 1987; Lazareno et al. , 1990; Tanda et al. , 2007). Telenzepine was perfused through the probe at $100 \mathrm{nM}$, in order to generate extracellular concentrations of about 10 nM (i.e. 3-10 fold greater than the affinity for M1 receptors). PD-102807 is an M4 preferential receptor antagonist, with 7-28 nM affinity for M4 receptors, a 14-36 fold selectivity for M4 over M3 receptors, and 76-2600 fold selectivity for M4 over M1, M2 and M5 receptors (Bohmeet al. , 2002; Croy et al. , 2016). PD102807 was perfused at $3 \mu \mathrm{M}$ to generate extracellular concentrations 10-30 greater than its affinity for M4 receptors and much lower than those for M1, M2 and M5 receptors. Tropicamide is considered an M4 preferential receptor antagonist, with an affinity of $15 \mathrm{nM}$ for the M4 receptors (Lazareno et al. , 1993; Lazareno et al. , 1990). However, its selectivity for the M4 receptor over M1, M2 and M3 receptors is only 3-fold (Lazarenoet al. , 1993; Lazareno et al. , 1990). In addition, a more recent study (Croy et al. , 2016) questioned even such small pharmacological preference. Thus, we decided to infuse $100 \mathrm{nM}$ tropicamide to generate concentrations just below the affinity value for the M4 receptor. VU0152100 is an M4 PAM effective in increasing by 70 -fold the potency of $\mathrm{ACh}$ to stimulate $\mathrm{Ca}^{2+}$ responses at M4 chimeric receptors (Brady et al. , 2008). It does not bind to the M4 orthosteric site nor it potentiates ACh binding to the other muscarinic receptor subtypes, thus appearing very selective for M4 receptors (Brady et al. , 2008). We perfused 100 $\mu \mathrm{M}$ through the probe to generate extracellular levels about 30 times higher than its $\mathrm{M} 4$ activity $\left(\mathrm{EC}_{50} 380\right.$ $\mathrm{nM})$. AFDX-116 is a preferential antagonist of M2 receptors showing nanomolar affinity for M2 receptors (pKi 6.7-7.5), 3-4-fold selectivity over M4 receptors, 4-10 fold selectivity over M1 and >10-fold selectivity over M5 receptors (Billardet al. , 1995; Doods et al. , 1987; Stoll et al. , 2009). The concentration used for reverse dialysis $(200 \mathrm{nM}$ ) was chosen based on a microdialysis study showing that perfusion of $100 \mathrm{nM}$ AFDX-116 through the probe was capable of increasing by $>70 \%$ ACh levels in striatum (Billard et al. , 1995). Based on the affinity values reported above, such concentration is expected to generate extracellular levels slightly below the highest affinity value found in functional studies (pKi 7.5)(Billard et al. , 1995).

Data and statistical analysis

The data and statistical analysis comply with the recommendations on experimental design and analysis in pharmacology (Curtis et al. , 2018). Since in microdialysis studies, particularly when amino acid are measured, baseline values can differ greatly from animal to animal, to minimize experimental variability data were normalized as percent of baseline values, as in our previous publications. Statistical analysis was performed (Graphpad Prism 6.0) on area-under-the curve values (AUC; calculated in the 100-220 min range) followed by the Newman-Keuls test for multiple comparisons. AIMs were statistically analysed using the Mann-Whitney U-test or the Kruskal-Wallis test followed by the Dunn test for multiple comparisons when more than two groups were compared. Alpha was set at 0.05 .

Materials

L-DOPA methyl ester, benserazide hydrochloride, tropicamide and VU-0152100 were purchased from SigmaAldrich (S. Louis MO, USA), 6-OHDA hydrobromide, telenzepine, PD-102807 and AFDX-116 from Tocris (Bristol, UK). Telenzepine, PD-102807, tropicamide, AFDX-116 and VU-0152100 were dissolved in Ringer for local perfusion through the microdialysis probe. 6-OHDA was dissolved in ascorbate-saline for intracerebral injection, whereas all the other drugs were dissolved in saline and administered systemically at the volume of $1.0 \mathrm{ml} / \mathrm{Kg}$ body weight.

\section{Results}

Striatal perfusion with telenzepine alleviated LID and inhibited nigral GABA and striatal Glu release

In order to evaluate whether M1 receptors influence LID and its neurochemical correlates, the M1 preferential antagonist telenzepine was perfused at the $100 \mathrm{nM}$ concentration through the probe implanted in striatum, 
starting from 40 minutes before systemic (s.c.) L-DOPA administration. Acute L-DOPA injection induced severe AIMs expression, which resulted $\sim 40 \%$ reduced by telenzepine $(\mathrm{U}=10.50, \mathrm{p}=0.022$; Fig. $1 \mathrm{~A})$. Basal dialysate values were $16.26 \pm 0.57 \mathrm{nM}(\mathrm{n}=208)$ and $63.09 \pm 2.09 \mathrm{nM}$ for GABA and Glu in SNr, respectively $(\mathrm{n}=208)$, and $57.79 \pm 2.48 \mathrm{nM}(\mathrm{n}=184)$ for Glu in striatum. LID expression was accompanied by the rise of nigral GABA $\left(\mathrm{F}_{2,21}=5.91, \mathrm{p}=0.0092\right.$; Fig. $\left.1 \mathrm{~B}\right)$ and $\mathrm{Glu}\left(\mathrm{F}_{2,21}=5.02, \mathrm{p}=0.0165\right.$; Fig. $\left.1 \mathrm{C}\right)$, as well as striatal Glu $\left(\mathrm{F}_{2,21}=6.06, \mathrm{p}=0.0084\right.$; Fig $\left.1 \mathrm{D}\right)$. Intrastriatal perfusion with telenzepine prevented the L-DOPA-induced rise of nigral GABA (Fig. 1B) and striatal Glu (Fig.1D), but not nigral Glu (Fig. 1C).

Striatal perfusion with PD-102807 and tropicamide alleviated LID and inhibited nigral GABA and Glu along with striatal Glu release

In order to evaluate whether striatal M4 receptors influence LID and its neurochemical correlates, the M4 preferential antagonist PD-102807 and the putative M4 preferential antagonist tropicamide were perfused through the probe implanted in striatum. PD-102807 $(3 \mu \mathrm{M})$ reduced LID expression by $\sim 60 \%$ (U=0.00, $\mathrm{p}=0.0009$; Fig. 2A), and inhibited the L-DOPA-induced rise of GABA $\left(\mathrm{F}_{2,21}=12.64, \mathrm{p}=0.0002\right.$; Fig. 2B) and Glu $\left(\mathrm{F}_{2,21}=8.93, \mathrm{p}=0.0016\right.$; Fig. $\left.2 \mathrm{C}\right)$ in $\mathrm{SNr}$, and Glu in striatum $\left(\mathrm{F}_{2,21}=14.04, \mathrm{p}=0.0001\right.$; Fig. $\left.2 \mathrm{D}\right)$. Likewise, tropicamide $(100 \mathrm{nM})$ attenuated LID expression by $\sim 50 \%(\mathrm{U}=24.50, \mathrm{p}=0.0163 ;$ Fig $3 \mathrm{~A})$ and simultaneously prevented the rise of GABA $\left(\mathrm{F}_{2,21}=8.04, \mathrm{p}=0.0025\right.$; Fig. $\left.3 \mathrm{~B}\right)$ and Glu $\left(\mathrm{F}_{2,21}=7.91 ; \mathrm{p}=0.0027\right.$; Fig. 3C) in $\mathrm{SNr}$ and the elevation of Glu in striatum $\left(\mathrm{F}_{2,21}=6.75 ; \mathrm{p}=0.0054\right.$; Fig. 3D) associated with LID appearance.

\section{Striatal perfusion with VU0152100 alleviated LID and inhibited nigral GABA and striatal Glu release}

Experimental evidence in mice and non-human primates showed that M4 receptor activation with M4 PAMs palliates LID (Shen et al. , 2015). In order to confirm this finding in rats and reveal the associated pathways, we perfused the M4 receptor PAM VU0152100 at $100 \mu \mathrm{M}$ through the probe implanted in striatum. Striatal perfusion of VU0152100 reduced LID by $40 \%$ ( $\mathrm{U}=7.50, \mathrm{p}=0.0076$; Fig.4A), and prevented the LID-associated nigral GABA $\left(\mathrm{F}_{2,21}=7.06, \mathrm{p}=0.0045\right.$; Fig. $\left.4 \mathrm{~B}\right)$ and $\mathrm{Glu}\left(\mathrm{F}_{2,21}=6.25, \mathrm{p}=0.0074\right.$; Fig. $\left.4 \mathrm{C}\right)$ surge. Unlike M4 preferential antagonists, intrastriatal VU0152100 did not affect the LID-associated increase of striatal Glu release $\left(\mathrm{F}_{2,21}=4.15, \mathrm{p}=0.0302\right.$; Fig. $\left.4 \mathrm{D}\right)$.

\section{Striatal perfusion with AFDX-116 blocked the antidyskinetic effect of PD-102807}

Striatal M4 receptors are predominantly located presynaptically on ChIs (autoreceptors) or postsynaptically on glutamatergic cortico-striatal terminals and striato-nigral MSNs. To investigate whether the behavioral and neurochemical effects induced by striatal perfusion with PD-102807 were due to pre- or post-synaptic mechanisms, we intrastriatally perfused PD-102807 in combination with the M2 preferential antagonist, AFDX-116 (100 nM). Indeed, this concentration of AFDX-116 has been shown to elevate striatal ACh levels (Billard et al. , 1995; Galarraga et al. , 1999) and affect MSNs postsynaptically (Galarraga et al. , 1999). We reasoned that if the effects of PD-102807 were mediated by M4 autoreceptor blockade and elevation of striatal ACh levels, M2 autoreceptor blockade by AFDX-116 would further enhance or, at most, leave unchanged the effects of PD-102807. On the contrary, if the effects of PD-102807 were induced by postsynaptic M4 receptor blockade, an increase of ACh release would reverse them. Striatal perfusion with AFDX-116 did not affect LID expression but prevented the antidyskinetic effect of PD-102807. In fact, in the presence of AFDX-116, PD-102807 failed to attenuate AIMs severity $(\mathrm{H}=4.29 \mathrm{p}=0.11$; Fig. 5A). Consistently, in the presence of AFDX-116, PD-102807 failed to inhibit the LID-associated rise of nigral GABA $\left(\mathrm{F}_{3,30}=7.89\right.$, $\mathrm{p}=0.0005$; Fig $5 \mathrm{~B})$ or $\mathrm{Glu}\left(\mathrm{F}_{3,30}=5.54, \mathrm{p}=0.0038\right.$; Fig. 5C). Surprisingly enough, however, AFDX-116 failed to prevent the PD-102807 inhibition of the LID-associated increase of striatal Glu release (Fig. 5D).

Nigral perfusion with VU0152100 alleviated LID and its neurochemical correlates whereas nigral perfusion with PD-102807 was ineffective

Nigral M4 receptors activated by cholinergic afferents from the PPN exert a powerful modulation of D1 receptor signaling at striato-nigral MSNs terminals in SNr (Moehle et al. , 2017). To prove this modulation is relevant to LID, VU0152100 $(100 \mu \mathrm{M})$ or PD-102807 $(3 \mu \mathrm{M})$ were perfused through the probe 
implanted in SNr. Nigral perfusion with VU0152100 reduced LID by $60 \%$, whereas PD-102807 was ineffective $(\mathrm{H}=16.50 \mathrm{p}=0.0003$ Fig. $6 \mathrm{~A})$. Intranigral VU0152100 also inhibited the LID-associated rise of nigral GABA $\left(\mathrm{F}_{2,21}=18.34, \mathrm{p}<0.0001\right.$; Fig.6B) and $\mathrm{Glu}\left(\mathrm{F}_{2,21}=4.99, \mathrm{p}=0.0168\right.$; Fig. $\left.6 \mathrm{C}\right)$ and, differently from striatal perfusion, also the LID-associated rise of Glu in striatum $\left(\mathrm{F}_{2,21}=6.31, \mathrm{p}=0.0071\right.$; Fig. $\left.6 \mathrm{D}\right)$. Consistent with its failure in modulating LID, intranigral PD-102807 did not influence the LID-associated increase of nigral $\operatorname{GABA}\left(\mathrm{F}_{2,21}=5.52, \mathrm{p}=0.0118\right.$; Fig. $\left.6 \mathrm{E}\right)$ and Glu $\left(\mathrm{F}_{2,21}=4.860, \mathrm{p}=0.0184\right.$; Fig. $\left.6 \mathrm{~F}\right)$.

\section{Discussion}

The role of striatal and nigral M1 and M4 muscarinic receptors in LID was investigated using a dual probe microdialysis approach (Mela et al. , 2012) by which M1 and M4 receptor preferential antagonists and a M4 receptor selective PAM were delivered through the microdialysis probe into the dorsolateral striatum or $\mathrm{SNr}$, simultaneously with systemic L-DOPA administration.

\section{Telenzepine in striatum}

Reverse dialysis of the M1 preferential antagonist telenzepine in striatum attenuated LID expression and the accompanying rise of GABA in SNr. Since previous microdialysis studies (Marti et al. , 2012; Mela et al. , 2012; Mela et al. , 2007) demonstrated that the rise of nigral GABA release which accompanies AIMs appearance reflects the activation of D1-expressing striato-nigral MSNs, it appears that M1 receptor stimulation contributes to LID expression and the underlying striato-nigral pathway activation. Indeed, M1 receptors increase striato-nigral and striato-pallidal MSNs excitability through different mechanisms: i) closure of Kir2 and KCNQ (Kv7) K ${ }^{+}$channels (Shenet al. , 2005), particularly in striato-pallidal MSNs (Shen et al. , 2007); ii) enhancement of $\mathrm{Ca}^{2+}$-currents through $\mathrm{Ca}_{\mathrm{v}} 1$ channels, particularly in striato-nigral MSNs (Hernandez-Flores et al. , 2015; Hernandez-Lopez et al. , 1997; Perez-Garci et al. , 2003); iii) facilitation of NMDA transmission (Calabresi et al. , 1998) through persistent sodium currents (Carrillo-Reidet al. , 2009); iv) inactivation of $\mathrm{N}-$ and $\mathrm{P} / \mathrm{Q} \mathrm{Ca} \mathrm{v}_{\mathrm{v}}$ channels, leading to reduced GABA release from striatal interneurons (Perez-Roselloet al. , 2005). Telenzepine was proposed to improve motor symptoms in parkinsonian mice, acting at striato-pallidal M1 receptors (Ztaou et al. , 2016). Our study would point to an inhibitory action of telenzepine at M1 receptors on striato-nigral MSNs. To possibly confirm this view, telenzepine also reduced the LID-associated elevation of striatal Glu release (Brugnoli et al. , 2016; Gardoni et al. , 2018; Ostock et al. , 2011; Paolone et al. , 2015). In fact, elevation of striatal Glu release might result from striato-nigral MSNs stimulation leading to activation of cortico-basal ganglia-thalamo-cortical loop (Market al. , 2004; Marti et al. , 2005) and cortico-striatal terminals (Ostock et al. , 2011; Paolone et al. , 2015). However, Glu might be also released from striatal ChIs, which express the vesicular Glu transporter 3 (VGLUT3) (Kljakic et al. , 2017), thus contributing to PD symptoms and LID (Divito et al. , 2015; Gangarossa et al. , 2016). Finally, Glu released from thalamo-striatal terminals stimulates striato-pallidal MSNs, thereby sustaining akinesia in parkinsonian mice (Tanimura et al. , 2019). Therefore, the reduction of striatal Glu in our model might not only reflect cortico-basal ganglia-thalamo-cortical loop inhibition but also normalization of ChIs activity and cortico/thalamo-striatal transmission, which might impact behaviors beyond dyskinesia. Indeed, high frequency stimulation of the subthalamic nucleus normalized the elevation of cortico-striatal glutamatergic transmission in dyskinetic rats, which was associated with motor improvement but not LID attenuation (Gubellini et al. , 2006). Moreover, inhibition of Glu release from thalamo-striatal Glu terminals (via nicotinic receptor desensitization) reduced the firing of striato-pallidal MSNs and improved PD-related motor learning deficits (Tanimura et al. , 2019). This might explain why striatal Glu release can sometimes dissociate from AIMs appearance. In fact, in dyskinetic rats chronically treated with the MAO-B and $\mathrm{Na}_{\mathrm{V}}$ channel inhibitor, safinamide (Gardoni et al. , 2018), or intrastriatally perfused with AFDX-116 and PD-102807 (present study) striatal Glu did not rise along with AIMs.

\section{VU0152100, PD-102807 and tropicamide in striatum}

Consistent with previous finding that M4 PAM VU0467154 attenuated LID and aberrant plasticity at striatonigral MSNs in mice and non-human primates (Shen et al. , 2015), reverse dialysis of VU0152100 in striatum reduced LID and striato-nigral MSNs activation in vivo. Quite unexpectedly, this was also replicated by 
reverse dialysis of the M4 preferential antagonist PD-102807 (and the putative M4 preferential antagonist tropicamide) in striatum, suggesting that both M4 receptor stimulation and blockade have the same outcome on LID and associated pathways. Since PD-102807 concentrations were chosen to generate extracellular levels $(\sim 300 \mathrm{nM}$ ) well below the affinity for the M1 receptor (1.3-1.6 $\mu \mathrm{M})$ (Bohme et al. , 2002; Croy et al. , 2016), it is unlikely that the effects of PD-102807 are due to an interaction with M1 receptors. Rather, the slight differences in the neurochemical patterns of VU0152100 with respect to M4 antagonists would point to an involvement of different sets of striatal M4 receptors. Striatal M4 receptors are expressed presynaptically on ChIs, where they operate as autoreceptors (Bonsi et al. , 2008; Zhang et al. , 2002), and postsynaptically, either on glutamatergic terminals where they inhibit Glu release (Pancani et al. , 2014), or striato-nigral MSNs where they modulate D1 signalling, $\mathrm{Ca}^{2+}$ channels, NMDA currents, and release endocannabinoids that retrogradely modulate DA release (Moehle et al. , 2019). Opposite actions have been attributed to postsynaptic M4 receptors at striato-nigral MSNs. In dissociated striato-nigral MSNs, M4 receptor stimulation enhanced excitability via opening of Cav1 channels, thus facilitating a subsequent stimulation induced by a D1 receptor agonist (Hernandez-Floreset al. , 2015). This is consistent with the increase of L-type $\mathrm{Ca}^{2+}$ currents mediated by M4 receptors in atrial cells (Pemberton et al. , 1995). Conversely, a negative interaction between M4 and D1 receptors on cAMP production, $\mathrm{Ca}^{2+}$ influx at dendritic NMDA receptors, and LTP modulation has been described at striato-nigral MSNs in slices (Shen et al. , 2015). Supporting a postsynaptic action at facilitatory M4 receptors on striato-nigral MSNs (Hernandez-Flores et al. , 2015), PD-102807 and tropicamide, in addition to LID and nigral GABA, also prevented the LID-associated elevation of nigral and striatal Glu, replicating the neurochemical profile of intrastriatal SCH23390, which blocks D1 receptors on striato-nigral MSNs (Mela et al. , 2012). Moreover, AFDX-116 counteracted LID and nigral GABA release inhibition induced by PD-102807, as if the elevation of striatal ACh levels produced by M2 autoreceptor blockade surmounted the postsynaptic M4 blockade and/or functionally counteracted it by overstimulating postsynaptic M1 receptors (Galarraga et al. , 1999). Finally, an fMRI study revealed that systemic M4 PAMs did not affect the D1 agonist-induced changes in cerebral blood volume (CBV), a hemodynamic response reflecting changes in neuronal activity, in striatum while inhibiting the amphetamine-induced CBV changes and DA release in the same area, along with the accompanying hyperlocomotion (Byun et al. , 2014). Thus, the main action of M4 PAMs in striatum has been proposed to be presynaptic, i.e. the modulation of DA release, and not postsynaptic (Moehle et al. , 2019; Moehle et al. , 2017). We can therefore speculate that VU0152100 reduced LID and striato-nigral MSNs activation by inhibiting ectopic DA release from serotonergic terminals, the predominant site of L-DOPA conversion to DA in the DA-depleted striatum (Bastide et al. , 2015), or even by rescuing M4 autoreceptor function in ChIs, which is inhibited due to upregulation of RGS4 proteins (Shenet al. , 2015). The failure of intrastriatal M4 PAM VU0152100 in modulating striatal Glu release would rule out the possibility that the inhibitory control operated by M4 receptors on Glu terminals (Pancani et al. , 2014) contributes to the antidyskinetic effect of VU0152100.

\section{VU0152100 and PD-102807 in SNr}

Intranigral reverse dialysis of VU0152100 prevented LID and the accompanying rise of nigral GABA release. This is consistent with the finding that M4 PAM VU0467154 inhibited the D1 agonist-induced GABA release from striato-nigral MSNs terminals in vitro, and $\mathrm{CBV}$ in $\mathrm{SNr}$ neurons in vivo (Moehle et al. , 2017). The profile of intranigral VU0152111 confirms the role of the cholinergic afferents arising from PPN in the modulation of $\mathrm{D} 1$ signaling in $\mathrm{SNr}$ (Moehle et al. , 2017) and shows that this modulation shapes LID. Indeed, the neurochemical responses to intranigral VU0152100, also considering the inhibition of striatal Glu, are consistent with the view that M4 receptor stimulation inhibits GABA release from striato-nigral MSN terminals, thus limiting the overinhibition of nigro-thalamic GABAergic neurons (i.e. the nigral output) associated with LID. In vitro electrophysiological experiments in nigral slices showed that the M4 inhibition of nigral D1 signalling and GABA release is tonically active (Moehle et al. , 2017). However, in the present in vivo model, blockade of nigral M4 receptors with tropicamide did not alter nigral LID and nigral GABA and Glu release, suggesting that endogenous ACh acting at nigral M4 receptors does not contribute to LID. Nonetheless, we should consider that LID is already maximal in these animals, thus making it difficult to 
capture further increase of AIMs.

Conclusive remarks

Previous studies showed that striatal ChIs contribute to LID (Bordia et al. , 2016; Ding et al. , 2011; Won et al. , 2014) and that unspecific muscarinic antagonists dicyclomine and atropine prevented LID expression (Bordia et al. , 2016; Ding et al. , 2011). Consistently, intrastriatal telenzepine, PD-102807 and tropicamide attenuated LID and striato-nigral MSNs activation, further indicating that that M1 and M4 receptors are involved. Moreover, in keeping with the view that muscarinic receptors also mediate an inhibitory action of endogenous ACh on LID (Bordia et al. , 2016), potentiation of cholinergic transmission at striatal M4 receptors resulted in significant LID and striato-nigral MSNs inhibition. This suggest that M4 receptors, possibly located on different neuronal elements, can both facilitate and inhibit LID. During LID, the action of endogenous ACh at postsynaptic M4 receptors seems to prevail. Nonetheless, pharmacological potentiation of striatal M4 transmission during LID favors/unmasks other sets of M4 receptors, located on different neuronal elements, shifting the cholinergic control towards LID inhibition. This adds to a similar control in SNr. In fact, in line with previous evidence that PPN cholinergic inputs to SNr affect basal ganglia functions (Moehle et al. , 2017; Xiao et al. , 2016), the present study shows for the first time that nigral M4 receptor stimulation inhibited LID and nigral output. Altogether, these data reinforce the view that the M4 receptor is a promising target in LID therapy (Moehle et al. , 2019), providing in vivo evidence for powerful M4 receptor modulation of striato-nigral MSNs at both the striatal and nigral levels.

\section{Author contributions}

$\mathrm{AB}$ and $\mathrm{CAP}$ performed surgery, microdialysis experiments and HPLC analysis; MM and AB conceived the study and wrote the manuscript.

Conflict of interests : AB is postdoc at the University of Ferrara, CAP is PhD student at the University of Ferrara, MM is employed by the University of Ferrara.

\section{REFERENCES}

Bastide MF, Meissner WG, Picconi B, Fasano S, Fernagut PO, Feyder M, et al. (2015). Pathophysiology of L-dopa-induced motor and non-motor complications in Parkinson's disease. Prog Neurobiol 132: 96-168.

Bernard V, Normand E, Bloch B (1992). Phenotypical characterization of the rat striatal neurons expressing muscarinic receptor genes. J Neurosci 12 (9):3591-3600.

Billard W, Binch H, 3rd, Crosby G, McQuade RD (1995). Identification of the primary muscarinic autoreceptor subtype in rat striatum as $\mathrm{m} 2$ through a correlation of in vivo microdialysis and in vitro receptor binding data. J Pharmacol Exp Ther 273 (1): 273-279.

Bohme TM, Augelli-Szafran CE, Hallak H, Pugsley T, Serpa K, Schwarz RD (2002). Synthesis and pharmacology of benzoxazines as highly selective antagonists at $\mathrm{M}(4)$ muscarinic receptors. J Med Chem 45 (14): 3094-3102.

Bonsi P, Martella G, Cuomo D, Platania P, Sciamanna G, Bernardi G, et al. (2008). Loss of muscarinic autoreceptor function impairs long-term depression but not long-term potentiation in the striatum. $J$ Neurosci28 (24): 6258-6263.

Bordia T, Perez XA (2019). Cholinergic control of striatal neurons to modulate L-dopa-induced dyskinesias.Eur J Neurosci 49 (6): 859-868.

Bordia T, Perez XA, Heiss J, Zhang D, Quik M (2016). Optogenetic activation of striatal cholinergic interneurons regulates L-dopa-induced dyskinesias. Neurobiol Dis91: 47-58.

Brady AE, Jones CK, Bridges TM, Kennedy JP, Thompson AD, Heiman JU, et al. (2008). Centrally active allosteric potentiators of the M4 muscarinic acetylcholine receptor reverse amphetamine-induced hyperlocomotor activity in rats.J Pharmacol Exp Ther 327 (3): 941-953. 
Brugnoli A, Napolitano F, Usiello A, Morari M (2016). Genetic deletion of Rhes or pharmacological blockade of mTORC1 prevent striato-nigral neurons activation in levodopa-induced dyskinesia. Neurobiol Dis 85: $155-163$.

Byun NE, Grannan M, Bubser M, Barry RL, Thompson A, Rosanelli J, et al. (2014). Antipsychotic druglike effects of the selective M4 muscarinic acetylcholine receptor positive allosteric modulator VU0152100. Neuropsychopharmacology39 (7): 1578-1593.

Calabresi P, Centonze D, Gubellini P, Pisani A, Bernardi G (2000). Acetylcholine-mediated modulation of striatal function. Trends Neurosci 23 (3):120-126.

Calabresi P, Centonze D, Gubellini P, Pisani A, Bernardi G (1998). Endogenous ACh enhances striatal NMDA-responses via M1-like muscarinic receptors and PKC activation.Eur J Neurosci 10 (9): 2887-2895.

Carrillo-Reid L, Tecuapetla F, Vautrelle N, Hernandez A, Vergara R, Galarraga E, et al. (2009). Muscarinic enhancement of persistent sodium current synchronizes striatal medium spiny neurons. J Neurophysiol102 (2): 682-690.

Cenci MA, Lee CS, Bjorklund A (1998). L-DOPA-induced dyskinesia in the rat is associated with striatal overexpression of prodynorphin- and glutamic acid decarboxylase mRNA.Eur J Neurosci 10 (8): 2694-2706.

Cenci MA, Lundblad M (2007). Ratings of L-DOPA-induced dyskinesia in the unilateral 6-OHDA lesion model of Parkinson's disease in rats and mice. Curr Protoc NeurosciChapter 9: Unit 925.

Chambers NE, Meadows SM, Taylor A, Sheena E, Lanza K, Conti MM, et al. (2019). Effects of Muscarinic Acetylcholine $\mathrm{m} 1$ and $\mathrm{m} 4$ Receptor Blockade on Dyskinesia in the Hemi-Parkinsonian Rat. Neuroscience 409: $180-194$.

Croy CH, Chan WY, Castetter AM, Watt ML, Quets AT, Felder CC (2016). Characterization of PCS1055, a novel muscarinic M4 receptor antagonist. Eur J Pharmacol 782:70-76.

Curtis MJ, Alexander S, Cirino G, Docherty JR, George CH, Giembycz MA, et al. (2018). Experimental design and analysis and their reporting II: updated and simplified guidance for authors and peer reviewers. Br J Pharmacol175 (7): 987-993.

Ding Y, Won L, Britt JP, Lim SA, McGehee DS, Kang UJ (2011). Enhanced striatal cholinergic neuronal activity mediates L-DOPA-induced dyskinesia in parkinsonian mice.Proc Natl Acad Sci USA 108 (2): 840-845.

Divito CB, Steece-Collier K, Case DT, Williams SP, Stancati JA, Zhi L, et al. (2015). Loss of VGLUT3 Produces Circadian-Dependent Hyperdopaminergia and Ameliorates Motor Dysfunction and l-Dopa-Mediated Dyskinesias in a Model of Parkinson's Disease. J Neurosci 35 (45): 14983-14999.

Doods HN, Mathy MJ, Davidesko D, van Charldorp KJ, de Jonge A, van Zwieten PA (1987). Selectivity of muscarinic antagonists in radioligand and in vivo experiments for the putative M1, M2 and M3 receptors. $J$ Pharmacol Exp Ther 242 (1): 257-262.

Galarraga E, Hernandez-Lopez S, Reyes A, Miranda I, Bermudez-Rattoni F, Vilchis C, et al. (1999). Cholinergic modulation of neostriatal output: a functional antagonism between different types of muscarinic receptors. J Neurosci19 (9): 3629-3638.

Gangarossa G, Guzman M, Prado VF, Prado MA, Daumas S, El Mestikawy S, et al. (2016). Role of the atypical vesicular glutamate transporter VGLUT3 in l-DOPA-induced dyskinesia. Neurobiol Dis 87: 69-79.

Gardoni F, Morari M, Kulisevsky J, Brugnoli A, Novello S, Pisano CA, et al. (2018). Safinamide Modulates Striatal Glutamatergic Signaling in a Rat Model of Levodopa-Induced Dyskinesia. J Pharmacol Exp Ther 367 (3): $442-451$. 
Gubellini P, Eusebio A, Oueslati A, Melon C, Kerkerian-Le Goff L, Salin P (2006). Chronic high-frequency stimulation of the subthalamic nucleus and L-DOPA treatment in experimental parkinsonism: effects on motor behaviour and striatal glutamate transmission. Eur J Neurosci 24 (6):1802-1814.

Hernandez-Flores T, Hernandez-Gonzalez O, Perez-Ramirez MB, Lara-Gonzalez E, Arias-Garcia MA, Duhne M, et al. (2015). Modulation of direct pathway striatal projection neurons by muscarinic M(4)-type receptors. Neuropharmacology 89: 232-244.

Hernandez-Lopez S, Bargas J, Surmeier DJ, Reyes A, Galarraga E (1997). D1 receptor activation enhances evoked discharge in neostriatal medium spiny neurons by modulating an L-type Ca2+ conductance. $J$ Neurosci 17 (9): 3334-3342.

Hersch SM, Gutekunst CA, Rees HD, Heilman CJ, Levey AI (1994). Distribution of m1-m4 muscarinic receptor proteins in the rat striatum: light and electron microscopic immunocytochemistry using subtypespecific antibodies. J Neurosci14 (5 Pt 2): 3351-3363.

Kljakic O, Janickova H, Prado VF, Prado MAM (2017). Cholinergic/glutamatergic co-transmission in striatal cholinergic interneurons: new mechanisms regulating striatal computation. J Neurochem 142 Suppl 2: 90102.

Lazareno S, Birdsall NJ (1993). Pharmacological characterization of acetylcholine-stimulated [35S]-GTP gamma S binding mediated by human muscarinic m1-m4 receptors: antagonist studies. $\mathrm{Br} J$ Pharmacol109 (4): 1120-1127.

Lazareno S, Buckley NJ, Roberts FF (1990). Characterization of muscarinic M4 binding sites in rabbit lung, chicken heart, and NG108-15 cells. Mol Pharmacol38 (6): 805-815.

Mark KA, Soghomonian JJ, Yamamoto BK (2004). High-dose methamphetamine acutely activates the striatonigral pathway to increase striatal glutamate and mediate long-term dopamine toxicity. $J$ Neurosci 24 (50): 11449-11456.

Marti M, Manzalini M, Fantin M, Bianchi C, Della Corte L, Morari M (2005). Striatal glutamate release evoked in vivo by NMDA is dependent upon ongoing neuronal activity in the substantia nigra, endogenous striatal substance P and dopamine.J Neurochem 93 (1): 195-205.

Marti M, Rodi D, Li Q, Guerrini R, Fasano S, Morella I, et al. (2012). Nociceptin/orphanin FQ receptor agonists attenuate L-DOPA-induced dyskinesias. J Neurosci 32 (46): 16106-16119.

Mela F, Marti M, Bido S, Cenci MA, Morari M (2012). In vivo evidence for a differential contribution of striatal and nigral D1 and D2 receptors to L-DOPA induced dyskinesia and the accompanying surge of nigral amino acid levels. Neurobiol Dis45 (1): 573-582.

Mela F, Marti M, Dekundy A, Danysz W, Morari M, Cenci MA (2007). Antagonism of metabotropic glutamate receptor type 5 attenuates l-DOPA-induced dyskinesia and its molecular and neurochemical correlates in a rat model of Parkinson's disease. J Neurochem 101 (2): 483-497.

Moehle MS, Conn PJ (2019). Roles of the M4 acetylcholine receptor in the basal ganglia and the treatment of movement disorders. Mov Disord 34 (8):1089-1099.

Moehle MS, Pancani T, Byun N, Yohn SE, Wilson GH, 3rd, Dickerson JW, et al. (2017). Cholinergic Projections to the Substantia Nigra Pars Reticulata Inhibit Dopamine Modulation of Basal Ganglia through the M4 Muscarinic Receptor.Neuron 96 (6): 1358-1372 e1354.

Morari M, O'Connor WT, Darvelid M, Ungerstedt U, Bianchi C, Fuxe K (1996). Functional neuroanatomy of the nigrostriatal and striatonigral pathways as studied with dual probe microdialysis in the awake rat-I. Effects of perfusion with tetrodotoxin and low-calcium medium. Neuroscience 72 (1): 79-87.

Ostock CY, Dupre KB, Jaunarajs KL, Walters H, George J, Krolewski D, et al. (2011). Role of the primary motor cortex in L-Dopa-induced dyskinesia and its modulation by 5 -HT1A receptor stimulation. 
Neuropharmacology61 (4): 753-760.

Pancani T, Bolarinwa C, Smith Y, Lindsley CW, Conn PJ, Xiang Z (2014). M4 mAChR-mediated modulation of glutamatergic transmission at corticostriatal synapses. ACS chemical neuroscience $\mathbf{5}$ (4): 318-324.

Paolone G, Brugnoli A, Arcuri L, Mercatelli D, Morari M (2015). Eltoprazine prevents levodopa-induced dyskinesias by reducing striatal glutamate and direct pathway activity. Mov Disord 30 (13): 1728-1738.

Paxinos G, Watson C (1986). The rat brain in stereotaxic coordinates . 2nd edn. Academic Press: Sydney ; Orlando.

Pemberton KE, Jones SV (1995). Enhancement of an L-type calcium current in AtT-20 cells; a novel effect of the m4 muscarinic receptor. Pflugers Arch429 (5): 699-707.

Perez-Garci E, Bargas J, Galarraga E (2003). The role of Ca2+ channels in the repetitive firing of striatal projection neurons. Neuroreport 14 (9):1253-1256.

Perez-Rosello T, Figueroa A, Salgado H, Vilchis C, Tecuapetla F, Guzman JN, et al. (2005). Cholinergic control of firing pattern and neurotransmission in rat neostriatal projection neurons: role of CaV2.1 and CaV2.2 Ca2+ channels. J Neurophysiol 93 (5): 2507-2519.

Pisani A, Bernardi G, Ding J, Surmeier DJ (2007). Re-emergence of striatal cholinergic interneurons in movement disorders. Trends Neurosci 30 (10):545-553.

Pisanò CA, Brugnoli A, Novello S, Caccia C, Keywood C, Melloni E, et al. (2020). Safinamide inhibits in vivo glutamate release in a rat model of Parkinson's disease. Neuropharmacology 167 .

Quik M, Bordia T, Zhang D, Perez XA (2015). Nicotine and Nicotinic Receptor Drugs: Potential for Parkinson's Disease and Drug-Induced Movement Disorders. Int Rev Neurobiol124: 247-271.

Shen W, Hamilton SE, Nathanson NM, Surmeier DJ (2005). Cholinergic suppression of KCNQ channel currents enhances excitability of striatal medium spiny neurons. J Neurosci 25 (32): 7449-7458.

Shen W, Plotkin JL, Francardo V, Ko WK, Xie Z, Li Q, et al. (2015). M4 Muscarinic Receptor Signaling Ameliorates Striatal Plasticity Deficits in Models of L-DOPA-Induced Dyskinesia. Neuron 88 (4): 762-773.

Shen W, Tian X, Day M, Ulrich S, Tkatch T, Nathanson NM, et al. (2007). Cholinergic modulation of Kir2 channels selectively elevates dendritic excitability in striatopallidal neurons. Nat Neurosci 10 (11):1458-1466.

Stoll C, Eltze M, Lambrecht G, Zentner J, Feuerstein TJ, Jackisch R (2009). Functional characterization of muscarinic autoreceptors in rat and human neocortex. J Neurochem 110 (3): 837-847.

Tanda G, Ebbs AL, Kopajtic TA, Elias LM, Campbell BL, Newman AH, et al. (2007). Effects of muscarinic M1 receptor blockade on cocaine-induced elevations of brain dopamine levels and locomotor behavior in rats. J Pharmacol Exp Ther321 (1): 334-344.

Tanimura A, Du Y, Kondapalli J, Wokosin DL, Surmeier DJ (2019). Cholinergic Interneurons Amplify Thalamostriatal Excitation of Striatal Indirect Pathway Neurons in Parkinson's Disease Models. Neuron 101 (3):444-458 e446.

Won L, Ding Y, Singh P, Kang UJ (2014). Striatal cholinergic cell ablation attenuates L-DOPA induced dyskinesia in Parkinsonian mice. J Neurosci34 (8): 3090-3094.

Xiao C, Cho JR, Zhou C, Treweek JB, Chan K, McKinney SL, et al. (2016). Cholinergic Mesopontine Signals Govern Locomotion and Reward through Dissociable Midbrain Pathways. Neuron 90 (2): 333-347.

Zhang W, Basile AS, Gomeza J, Volpicelli LA, Levey AI, Wess J (2002). Characterization of central inhibitory muscarinic autoreceptors by the use of muscarinic acetylcholine receptor knock-out mice. J Neurosci22 (5): $1709-1717$. 
Ztaou S, Maurice N, Camon J, Guiraudie-Capraz G, Kerkerian-Le Goff L, Beurrier C, et al.(2016). Involvement of Striatal Cholinergic Interneurons and M1 and M4 Muscarinic Receptors in Motor Symptoms of Parkinson's Disease. J Neurosci 36 (35): 9161-9172.

\section{Figure legends}

Figure 1. Behavioral and neurochemical effects of reverse dialysis of telenzepine in the dopamine-depleted striatum of dyskinetic rats undergoing microdialysis. Dyskinetic rats were implanted with one probe in the lesioned dorsolateral striatum and another in ipsilateral substantia nigra reticulata (SNr). Twenty-four hours later, rats received an acute challenge with L-DOPA alone (6 mg kg-1 plus $12 \mathrm{mg} \mathrm{kg}^{-1}$ benserazide, i.p.) or in combination with telenzepine $(100 \mathrm{nM})$ through the probe. Telenzepine perfusion started 40 min prior to L-DOPA administration and continued until the end of experiment. A group treated with telenzepine alone was also included. ALO AIMs were scored for 1 min every 20 min over 120 min after L-DOPA administration, then cumulative ALO AIMs calculated (A). Dialysate samples were collected every 20 min for 120 min after L-DOPA administration, and GABA (B) and glutamate (Glu; C-D) levels in dialysates were monitored in $\mathrm{SNr}$ and striatum. Data are means \pm SEM of 8 rats per group. Data were statistically analyzed as cumulative ALO AIMs score using the Mann-Whitney test (A) or as AUC values using ANOVA followed by the NewmanKeuls test (B-D). ${ }^{*} \mathrm{p}<0.05$ different from Ringer + L-DOPA $6 \mathrm{mg} \mathrm{Kg}{ }^{-1} ;{ }^{\circ} \mathrm{p}<0.05,{ }^{\circ} \mathrm{p}<0.01$, different from Telenzepine $100 \mathrm{nM}+$ saline.

Figure 2. Behavioral and neurochemical effects of reverse dialysis of PD-102807 in the dopamine-depleted striatum of dyskinetic rats undergoing microdialysis. Dyskinetic rats were implanted with one probe in the lesioned dorsolateral striatum and another in ipsilateral substantia nigra reticulata (SNr). Twenty-four hours later, rats received an acute challenge with L-DOPA alone (6 mg kg-1 plus $12 \mathrm{mg} \mathrm{kg}^{-1}$ benserazide, i.p.) or in combination with PD-102807 $(3 \mu \mathrm{M})$ through the probe. PD-102807 perfusion started 40 min prior to L-DOPA administration and continued until the end of experiment. A group treated with PD-102807 alone was also included. ALO AIMs were scored for 1 min every 20 min over 120 min after L-DOPA administration, then cumulative ALO AIMs calculated (A). Dialysate samples were collected every 20 min for 120 min after L-DOPA administration, and GABA (B) and glutamate (Glu; C-D) levels in dialysates were monitored in $\mathrm{SNr}$ and striatum. Data are means $\pm \mathrm{SEM}$ of 8 rats per group. Data were statistically analyzed as cumulative ALO AIMs score using the Mann-Whitney test (A) or as AUC values using ANOVA followed by the Newman-Keuls test (B-D). ${ }^{* *} \mathrm{p}<0.01$ different from Ringer + L-DOPA $6 \mathrm{mg} \mathrm{Kg}{ }^{-1} ;{ }^{\circ} \mathrm{p}<0.01$, different from PD-102807 $3 \mu \mathrm{M}+$ saline.

Figure 3. Behavioral and neurochemical effects of reverse dialysis of tropicamide in the dopamine-depleted striatum of dyskinetic rats undergoing microdialysis. Dyskinetic rats were implanted with one probe in the lesioned dorsolateral striatum and another in ipsilateral substantia nigra reticulata ( $\mathrm{SNr}$ ). Twenty-four hours later, rats received an acute challenge with L-DOPA alone $\left(6 \mathrm{mg} \mathrm{kg}^{-1}\right.$ plus $12 \mathrm{mg} \mathrm{kg}^{-1}$ benserazide, i.p.) or in combination with tropicamide $(100 \mathrm{nM})$ through the probe. Tropicamide perfusion started 40 min prior to L-DOPA administration and continued until the end of experiment. A group treated with tropicamide alone was also included. ALO AIMs were scored for 1 min every 20 min over 120 min after L-DOPA administration, then cumulative ALO AIMs calculated (A). Dialysate samples were collected every $20 \mathrm{~min}$ for 120 min after L-DOPA administration, and GABA (B) and glutamate (Glu; C-D) levels in dialysates were monitored in SNr and striatum. Data are means \pm SEM of 8 rats per group. Data were statistically analyzed as cumulative ALO AIMs score using the Mann-Whitney test (A) or as AUC values using ANOVA followed by the Newman-Keuls test (B-D). ${ }^{*} \mathrm{p}<0.05,{ }^{* *} \mathrm{p}<0.01$, different from Ringer + L-DOPA $6 \mathrm{mg} \mathrm{Kg}^{-1}$; ${ }^{\circ} \mathrm{p}<0.01$, different from Tropicamide $100 \mathrm{nM}+$ saline.

Figure 4. Behavioral and neurochemical effects of reverse dialysis of VU0152100 in the dopamine-depleted striatum of dyskinetic rats undergoing microdialysis. Dyskinetic rats were implanted with one probe in the lesioned dorsolateral striatum and another in ipsilateral substantia nigra reticulata (SNr). Twenty-four hours later, rats received an acute challenge with L-DOPA alone (6 mg kg-1 plus $12 \mathrm{mg} \mathrm{kg}^{-1}$ benserazide, i.p.) or in combination with VU0152100 $(100 \mu \mathrm{M})$ through the probe. VU0152100 perfusion started 40 min prior to L-DOPA administration and continued until the end of experiment. A group treated with VU0152100 
alone was also included. ALO AIMs were scored for 1 min every 20 min over 120 min after L-DOPA administration, then cumulative ALO AIMs calculated (A). Dialysate samples were collected every $20 \mathrm{~min}$ for 120 min after L-DOPA administration, and GABA (B) and glutamate (Glu; C-D) levels in dialysates were monitored in SNr and striatum. Data are means \pm SEM of 8 rats per group. Data were statistically analyzed as cumulative ALO AIMs score using the Mann-Whitney test (A) or as AUC values using ANOVA followed by the Newman-Keuls test (B-D). ${ }^{*} \mathrm{p}<0.05 ;{ }^{* *} \mathrm{p}<0.01$ different from Ringer + L-DOPA $6 \mathrm{mg} \mathrm{Kg}^{-1}$; ${ }^{\circ} \mathrm{p}<0.05,{ }^{\circ} \mathrm{p}<0.01$, different from VU0152100 $100 \mu \mathrm{M}+$ saline.

Figure 5. Behavioral and neurochemical effects of reverse dialysis of AFDX-116 in the dopamine-depleted striatum of dyskinetic rats undergoing microdialysis. Dyskinetic rats were implanted with one probe in the lesioned dorsolateral striatum and another in ipsilateral substantia nigra reticulata ( $\mathrm{SNr}$ ). Twenty-four hours later, rats received an acute challenge with L-DOPA alone (6 mg kg-1 plus $12 \mathrm{mg} \mathrm{kg}^{-1}$ benserazide, i.p.) or in combination with AFDX-116 (200 nM) or AFDX-116 (200 nM) + PD-102807 (3 $\mu \mathrm{M})$ through the probe. PD-102807 perfusion started 40 min prior to L-DOPA administration whereas perfusion with AFDX-116 started 60 min prior to L-DOPA or 20 min prior to PD-102807 and continued until the end of experiment. A group treated with AFDX-116 alone was also included. ALO AIMs were scored for 1 min every 20 min over 120 min after L-DOPA administration, then cumulative ALO AIMs calculated (A). Dialysate samples were collected every $20 \mathrm{~min}$ for $120 \mathrm{~min}$ after L-DOPA administration, and GABA (B) and glutamate (C-D) levels in dialysates were monitored in striatum and SNr. Data are means \pm SEM of 8 rats per group. Data were statistically analyzed as cumulative ALO AIMs score using the the Mann-Whitney test (A) or as AUC values using ANOVA followed by the Newman-Keuls test $(\mathrm{B}-\mathrm{F}) .{ }^{*} \mathrm{p}<0.05,{ }^{*} \mathrm{p}<0.01$ different from Ringer + L-DOPA; \# $\mathrm{p}<0.05$ different from PD-102807 $3 \mu \mathrm{M}+\mathrm{L}-\mathrm{DOPA} ;{ }^{\circ} \mathrm{p}<0.05 ;{ }^{\circ} \mathrm{p}<0.01$ different from VU0152100 $100 \mu \mathrm{M}+$ saline (B-D) or PD-102807 $3 \mu \mathrm{M}+$ saline (E-F).

Figure 6. Behavioral and neurochemical effects of reverse dialysis of VU0152100 or PD-102807 in the substantia nigra pars reticulata $(\mathrm{SNr})$ of dyskinetic rats undergoing microdialysis. Dyskinetic rats were implanted with one probe in the lesioned dorsolateral striatum and another in ipsilateral SNr. Twenty-four hours later, rats received an acute challenge with L-DOPA alone (6 mg kg-1 plus $12 \mathrm{mg} \mathrm{kg}^{-1}$ benserazide, i.p.) or in combination with VU0152100 $(100 \mu \mathrm{M})$ or PD-102807 $(3 \mu \mathrm{M})$ through the nigral probe. VU0152100 or PD-102807 perfusion started 40 min prior to L-DOPA administration and continued until the end of experiment. A group treated with VU0152100 or PD-102807 alone were also included. ALO AIMs were scored for 1 min every 20 min over 120 min after L-DOPA administration, then cumulative ALO AIMs calculated (A). Dialysate samples were collected every $20 \mathrm{~min}$ for $120 \mathrm{~min}$ after L-DOPA administration, and GABA (B, E) and glutamate (Glu; B-F) levels in dialysates were monitored in $\mathrm{SNr}$ or striatum. Data are means \pm SEM of 8 rats per group. Data were statistically analyzed as cumulative ALO AIMs score using the Kruskal-Wallis test for non parametric ANOVA followed by the Dunn test (A) or as AUC values using ANOVA followed by the Newman-Keuls test $(\mathrm{B}-\mathrm{F}){ }^{*} \mathrm{p}<0.05,{ }^{*} \mathrm{p}<0.01$ different from Ringer + L-DOPA; $\# \mathrm{p}<0.05$ different from PD-102807 $3 \mu \mathrm{M}+\mathrm{L}-\mathrm{DOPA} ;{ }^{\circ} \mathrm{p}<0.05 ;{ }^{\circ} \mathrm{p}<0.01$ different from VU0152100 $100 \mu \mathrm{M}$ + saline (B-D) or PD-102807 $3 \mu \mathrm{M}+$ saline (E-F). 

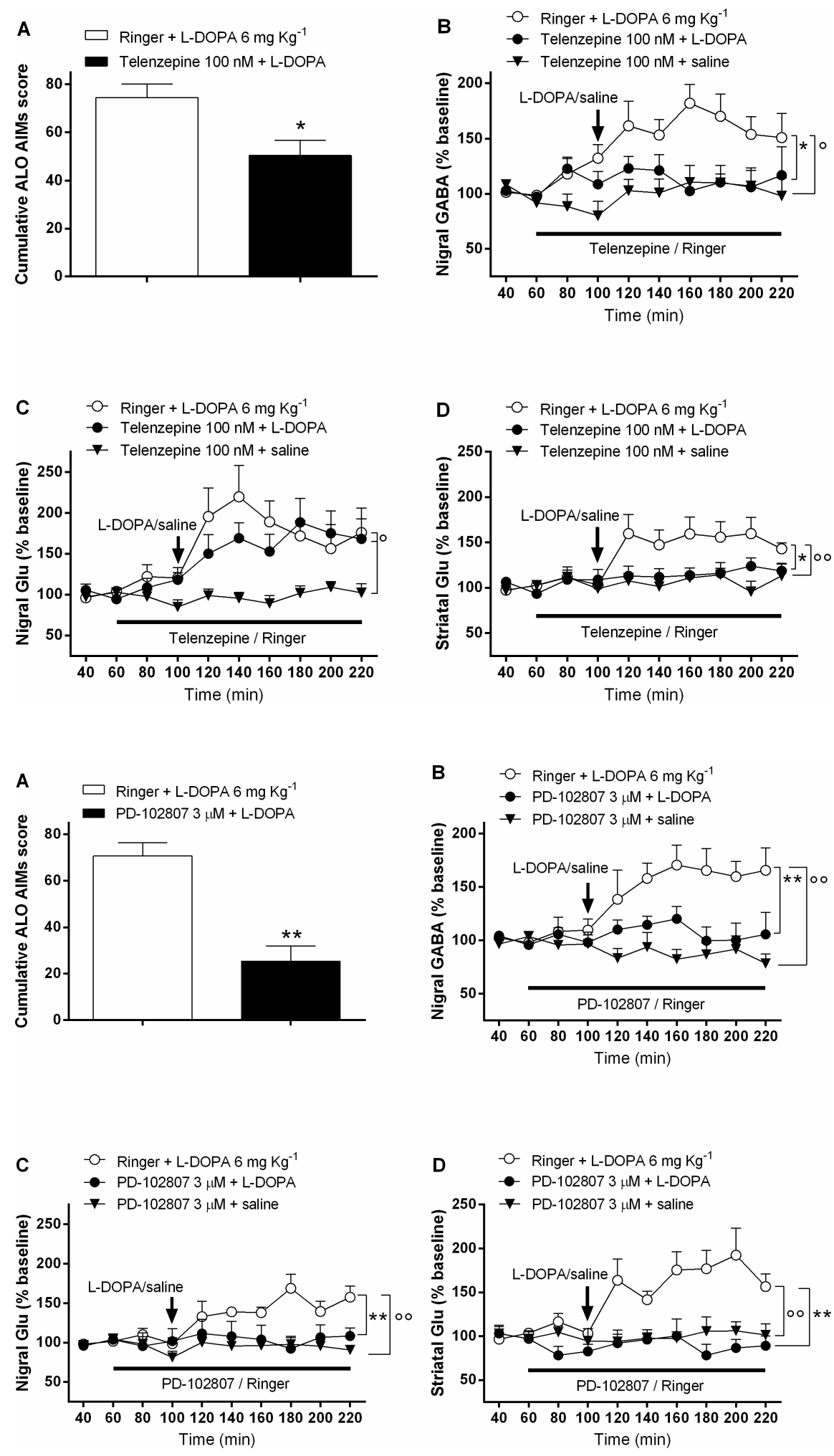

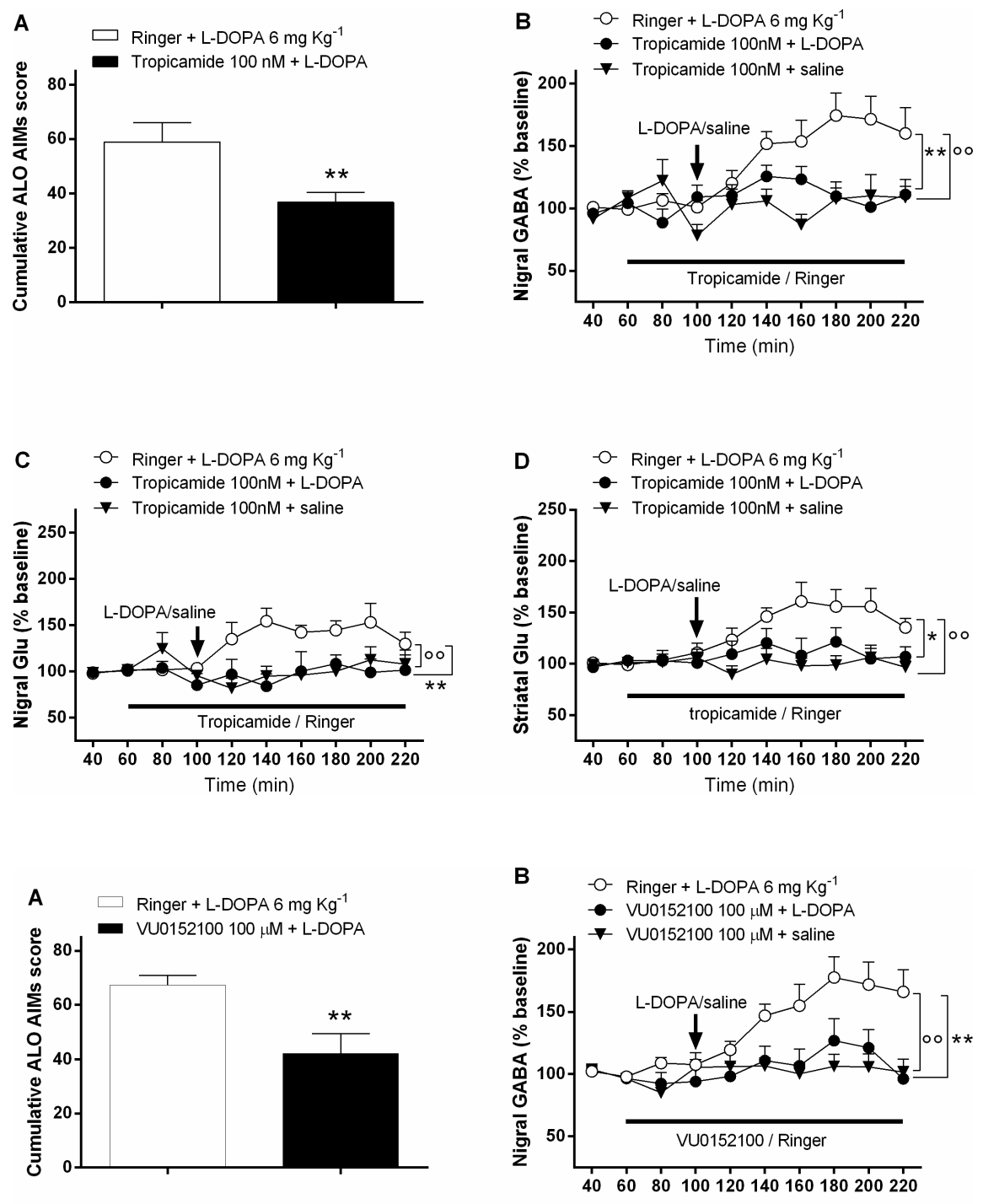

Time (min)
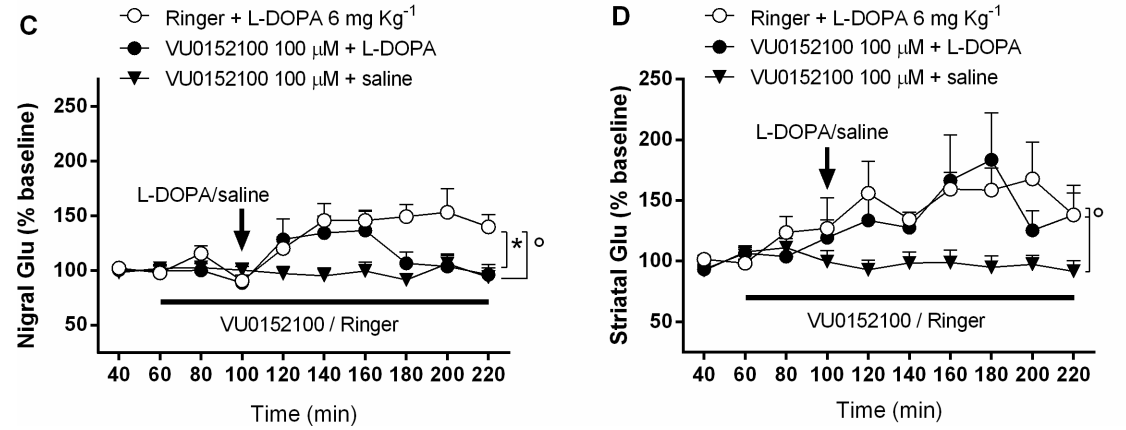
A $\square$ Ringer + L-DOPA $6 \mathrm{mg} \mathrm{Kg}^{-1}$

- AFDX-116 $200 \mathrm{nM}+$ L-DOPA

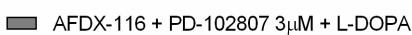

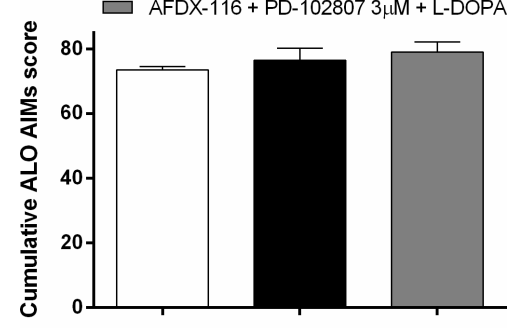

C

-O- Ringer + L-DOPA $6 \mathrm{mg} \mathrm{Kg}^{-1}$

- AFDX-116 $200 \mathrm{nM}+$ L-DOPA

-O- AFDX-116 + PD-102807 $3 \mu \mathrm{M}+$ L-DOPA

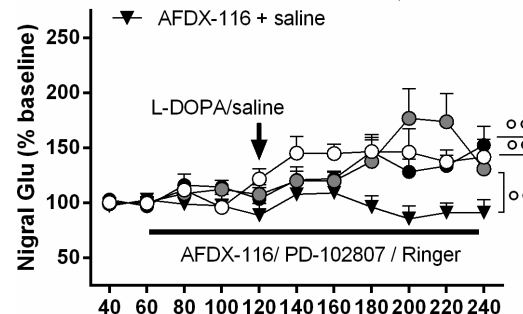

406080100120140160180200220240

Time (min)
B $\quad-$ Ringer + L-DOPA $6 \mathrm{mg} \mathrm{kg}^{-1}$

- AFDX-116 $200 \mathrm{nM}+\mathrm{L}-\mathrm{DOPA}$

- AFDX-116 + PD-102807 $3 \mu \mathrm{M}+$ L-DOPA

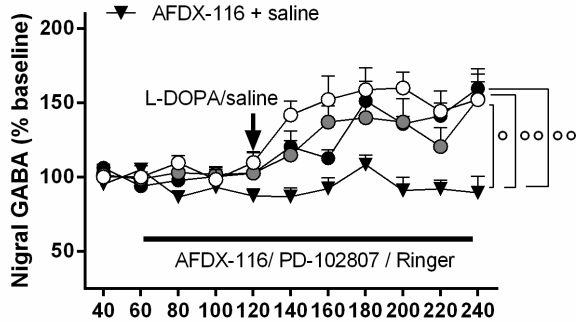

Time (min)

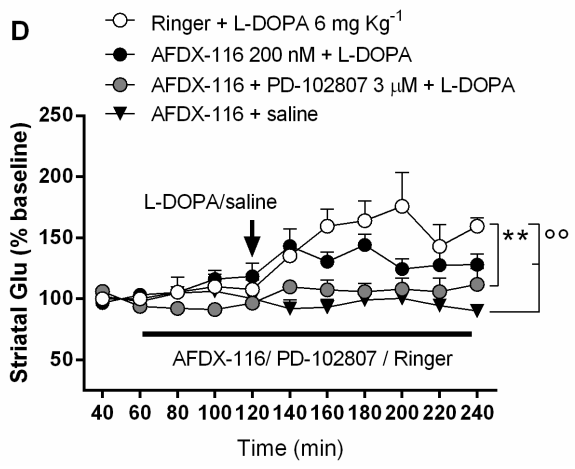



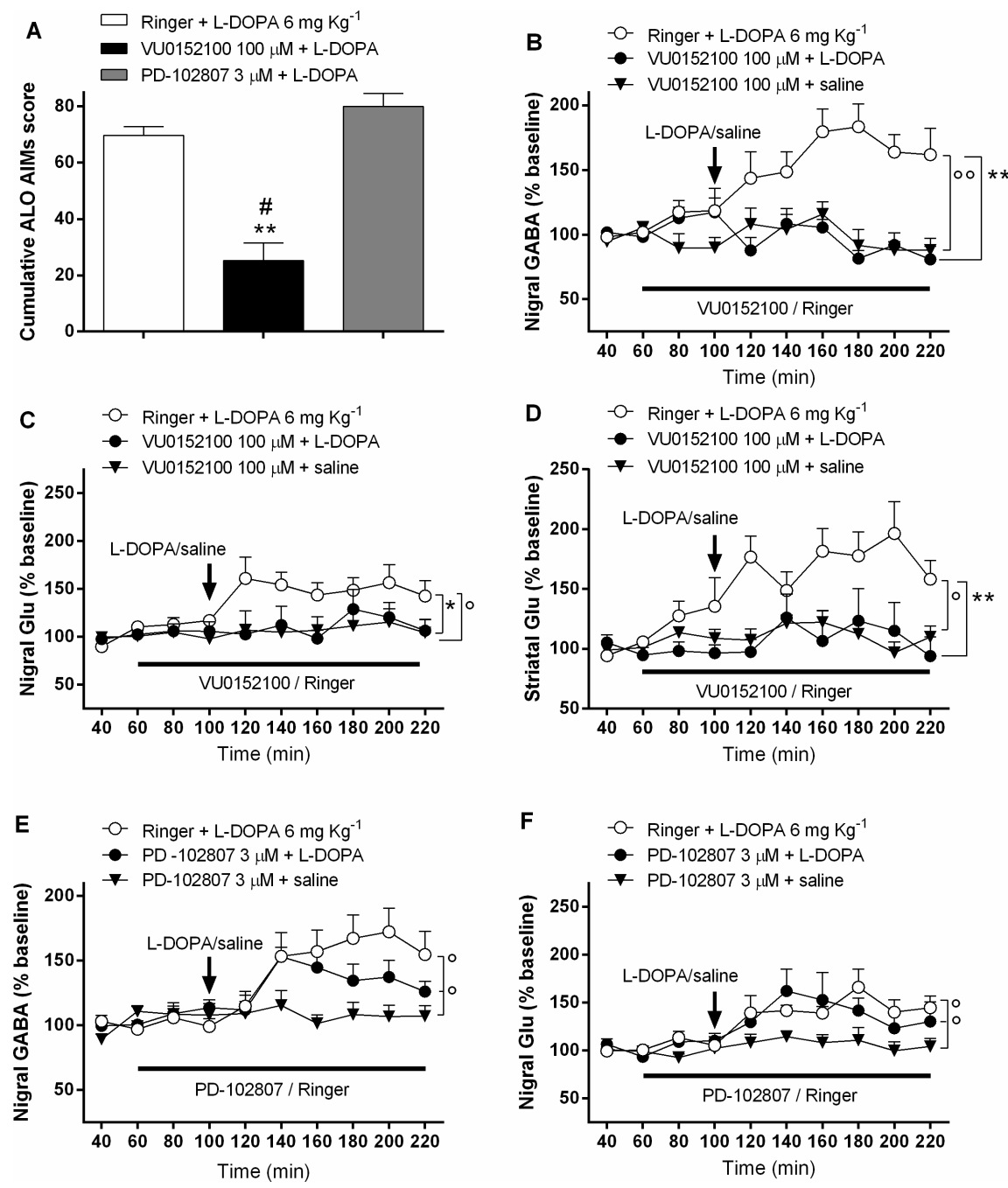